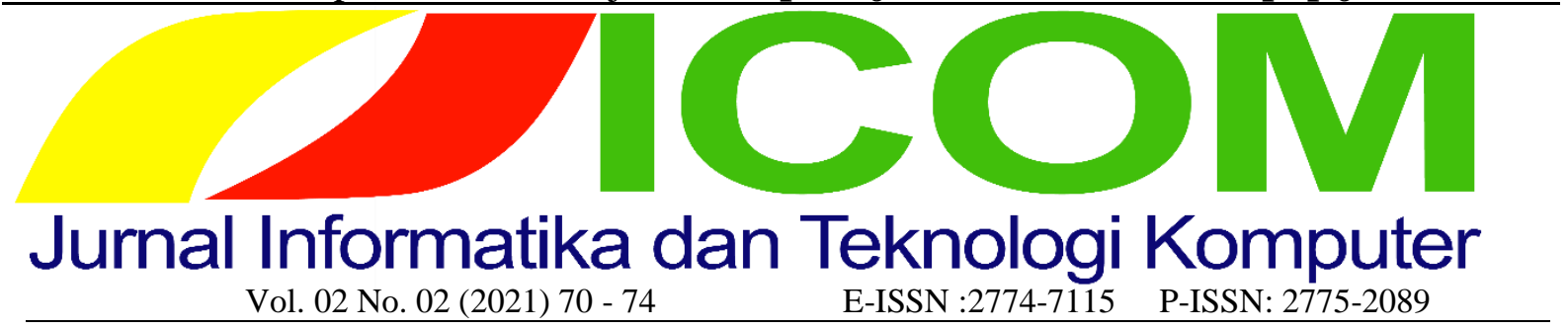

\title{
ANALISIS SISTEM APLIKASI SUPPLY CHAIN MANAGEMENT TELKOM (SCMT) UNTUK TEKNISI DI PT TELKOM KANDATEL LANGSA
}

\author{
Tesa Asmita ${ }^{1}$, Rizalul Akram² \\ Informatika, Teknik, Universitas Samudra \\ Informatika, Teknik, Universitas Samudra \\ ${ }^{1}$ tesaasmita09@gmail.com, ${ }^{2}$ rizalulakram@unsam.ac.id
}

\begin{abstract}
Application systems are a sub class of software that take advantage of the ability of a computer directly to perform a task that the user wants. PT. Telkom Indonesia (Persero) Tbk (Telkom) is a State-Owned Enterprise (BUMN) engaged in information and communication technology (ICT) services and telecommunications networks in Indonesia. PT Telkom also provides the procurement of materials and services for the installation of internet network devices. Development of an application system for checking the activation of the installation of material goods to customers and can assist the admin in checking the activation of the installation of material goods to customers. The development of the SCMT application has succeeded in checking the activation of the installation of material goods to customers. That way the admin can see the activation of the installation of material goods to customers. The development of the SCMT application is made using DFD to help understand the application system, and the development of this application uses ERD to determine relationships between tables.
\end{abstract}

Keywords: Application, SCMT, ERD

\begin{abstract}
Abstrak
Sistem Aplikasi adalah sub kelas dari perangkat lunak (software) yang memanfaatkan kemampuan komputer langsung untuk melakukan suatu tugas yang diinginkan pengguna. PT. Telkom Indonesia (Persero) Tbk (Telkom) adalah Badan Usaha Milik Negara (BUMN) yang bergerak di bidang jasa layanan teknologi informasi dan komunikasi (TIK) dan jaringan telekomunikasi di Indonesia. PT Telkom juga menyediakan pengadaan bahan dan pelayanan untuk pemasangan perangkat jaringan internet. Pengembangan sistem aplikasi pengecekan aktivasi pemasangan barang material ke pelanggan dan dapat membantu admin dalam melakukan proses pengecekan aktivasi pemasangan barang material ke pelanggan. Pengembangan aplikasi SCMT ini telah berhasil melakukan pengecekan aktivasi pemasangan barang material ke pelanggan. Dengan begitu admin dapat melihat aktivasi pemasangan barang material ke pelangan. Pengembangan aplikasai SCMT ini di buat menggunakan DFD untuk membantu memahami sistem aplikasi, serta pengembangan aplikasi ini menggunakan ERD untuk menentukan relasi antar tabel.
\end{abstract}

Kata kunci: Aplikasi, SCMT, ERD

\section{PENDAHULUAN}

Sistem Aplikasi adalah sub kelas dariperangkat lunak (software) yang memanfaatkan kemampuan komputer langsung untuk melakukan suatu tugas yang diinginkan pengguna.

PT. Telkom Indonesia (Persero) Tbk (Telkom) adalah Badan Usaha Milik Negara (BUMN) yang bergerak di bidang jasa layanan teknologi informasi dan komunikasi (TIK) dan jaringan telekomunikasi di Indonesia. PT Telkom juga menyediakan pengadaan bahan dan pelayanan untuk pemasangan perangkat jaringan internet.

Pada PT. Telkom kandatel langsa sudah memiliki sebuah aplikasi bernama SCMT (Supply Chain Management Telkom). Supply Chain Management Telkom (SCMT) digunakan oleh PT Telkom agar 
mempermudah Costumer untuk melakukan transaksi pembelian barang - barang material dengan jumlah banyak dan dengan pengirimanan barang material berkualitas tinggi cepat dan aman. SCMT lebih memudahkan pemasok untuk mengetahui barang yang akan di pesan oleh costumer. Pada aplikasi tersebut pemasangan perangkat jaringan internet kerap mengalami gangguan pemesanan dan pengiriman barang. Sehinggah menyebabkan keterlambatan dalam pemesanan dan pengiriman barang, serta aplikasi tersebut belum memiliki aplikasih untuk melihat data aktivasi pemasangan barang material pelanggan.

Permasalahan tersebut perlu adanya peningkatan akan pengembangkan aplikasi untuk melihat data aktivasi pemasangan barang material pelanggan. Sehingga memudahkan admin untuk melihat data aktivasi pemasangan barang material ke pelanggan. yaitu:

Adapun tujuan yang di buat dari sistem aplikasi

Pengembangan sistem aplikasi pengecekan aktivasi pemasangan barang material ke pelanggan dan dapat membantu admin dalam melakukan proses pengecekan aktivasi pemasangan barang material ke pelanggan.

Adapun manfaat yang di dapat dari sistem aplikasi yaitu:

Pengembangan sistem aplikasi dapat membantu Admin dalam melakukan pengecekan aktivasi pemasangan barang material ke pelanggan

\section{METODE PENELITIAN}

Supply Chain Management Telkom (SCMT) merupakan salah satu konsep pengelolaan aktivitas produksi pada PT Telkom melalui integrasi yang terbentuk di antaranya pemasok (supplier), pembuat (producer-manufacture), penyalur (distributor), gudang (warehouse), dan penjual (retail) serta konsumen, sehingga diperoleh suatu pola distribusi produk dengan jumlah, lokasi dan waktu yang tepat yang pada akhirnya dapat meminimalisasi biaya dengan tetap meningkatkan pelayanan kepada konsumen.

Berikut konsep penggolahan aktivitas produksi:
a) Supplier
b) Producer-manufacture
c) Distributor
d) Warehouse
e) Retail

Berikut Kelebihan dan kekurangan Aplikasi SCMT:

Kelebihan:

1. Aplikasi SCMT lebih memudahkan Admin atau PO untuk order barang material.

2. Admin lebih mudah melihat barang yang masih aktif atau belum aktif

3. Pemesanan lebih mudah dilakukan oleh admin karena tidak membutuhkan proses yang lama.

\section{Kekurangan:}

1. Aplikasi SCMT tidak dapat menampakan laporan barang material yang sudah di pasang telah aktif.

Alur pemakaian aplikasi SCMT

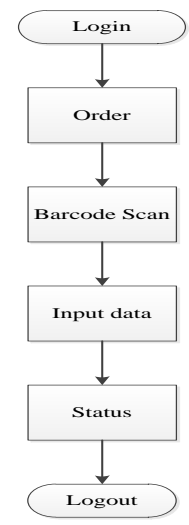

Alur pemakaian aplikasi SCMT

\section{HASIL DAN PEMBAHASAN}

\subsection{Pengembangan Aplikasi SCMT}

Tahapan pengembangan Aplikasi SCMT dibuat untuk melihat data aktivasi pemasangan barang material pelanggan, yang dijabarkan dalam bentuk berikut ini:

\section{Context Diagram}

Pada gambar dibawah terdapat dua actor yang akan terlibat dalam pengembangan aplikasi Supply Chain Management Telkom (SCMT) yaitu admin dan warehouse. Admin yang berfungsi untuk memanajemen data, dimana admin dapat menginput data order dan juga data transaksi. Lalu sistem akan mengeluarkan output berupa info order dan info data transaksi, admin juga dapat melihat Data Aktivasi yang di laporkan teknisi untuk memudahkan admin melihat system yang telah di aktivkan. Dan system akan mengirimkan Info data order kepada Warehouse, warehouse dapat melihat info data order dan info transaksi. 


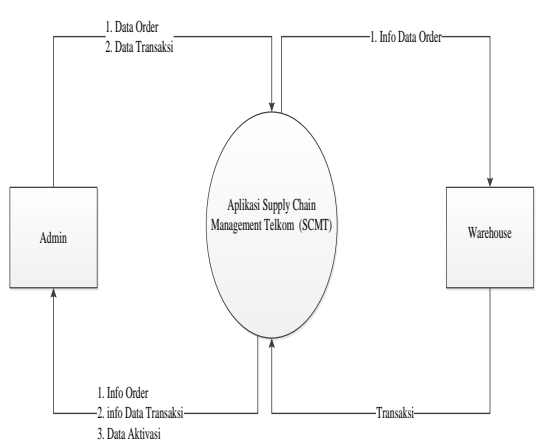

Gambar Diagram Konteks

\section{Data Flow Diagram (DFD) Level 0}

Pada gambar diatas dalam pengolahan sistem terdapat 5 proses, yaitu:

$\begin{array}{ll}\text { 1) } & \text { Proses Login } \\ \text { 2) } & \text { Order } \\ \text { 3) } & \text { Transaksi } \\ \text { 4) } & \text { Laporan } \\ \text { 5) } & \text { Logout }\end{array}$

Admin melakukan login dan data Admin masuk ke table Data Login, lalu admin melakukan Order dimana admin dapat mengelola data order dan data order di simpan di tabel data order, Berikutnya proses transaksi, dimana transaksi dapat dilakukan oleh admin , lalu hasil transaksi akan dikirm ke Warehouse dan data transaksi disimpan di table transaksi. Berikutnya proses laporan, ketika Admin telah melakukan transaksi dan hasil transaksi di simpan di table data transiksi maka data transaksi akan memberikan laporan, lalu teknisi akan memberikan laporan untuk dikirim ke admin dan admin akan melihat laporan keterangan apakah barang material yang di pasang sudah aktif atau belum aktiv oleh teknisi untuk pelangan, lalu laporan dari teknisi dapat di simpan berupa print data oleh admin dan dijadikan arsip file Terakhir admin dapat melakukan proses Logout.

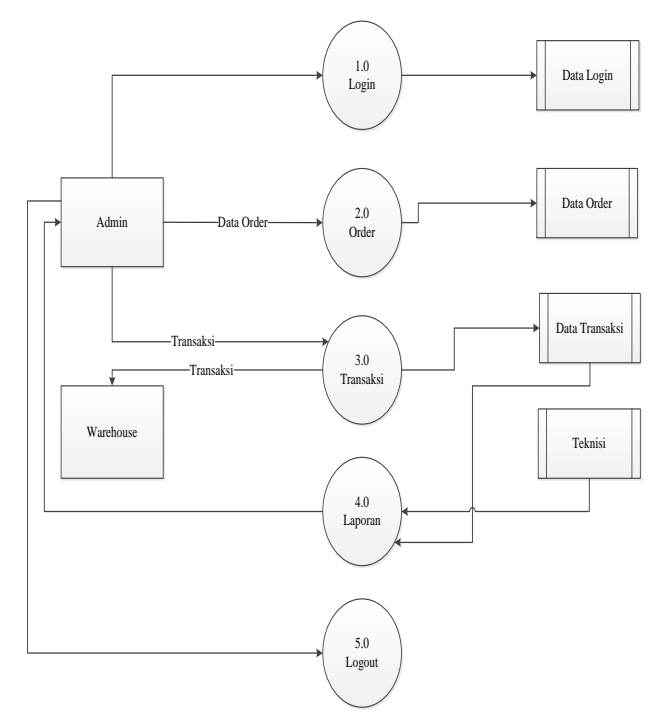

Gambar Data Flow Diagram (DFD) Level 0

\section{Entity Relationship Diagram (ERD)}

Entity Relationship Diagram (ERD) menjelaskan antara data dalam sistem basis data. Diagram ini merupakan penjabaran dari hubungan proses alur dari Admin menginput data, Admin menginput data yang akan di ganti statusnya untuk pengaktivan barang material yang di pasang teknisi.

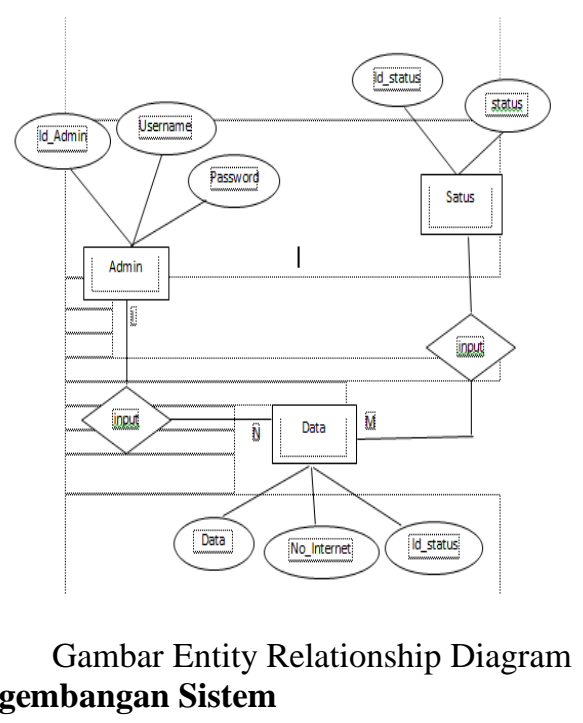

\section{Form Login}

Sebelum menginput dapa, terlebih dahulu masuk ke form login. Pada form login Admin harus mengisikan username dan password terlebih dahulu. 


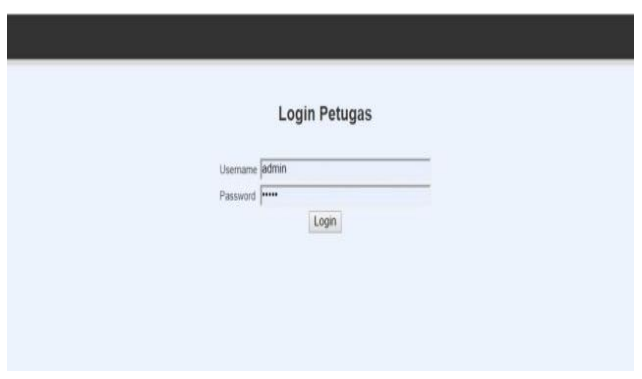

Gambar Form Login

\section{Form Menu Utama}

Pada form menu utama jika user sebagai admin, beberapa sub menu diantaranya Data Aktivasi, Input Status, Input Data lalu disertai dengan button logout yang digunakan jika Admin akan keluar dari sistem.

\section{Selamat Datang di PT. Telkom Kota Langsa \\ Telkom Indonesıa}

Gambar Form Menu Utama

\section{Form Input Data}

Pada form Input Data, ada beberapa perintah pengisian yaitu No Internet, Status dan submit Lalu data aktivasi yang ditampilkan yaitu meliputi: no internet pelanggan, Status aktif dan tidak aktif pemasangan barang material, dan perintah pngisian yang akan dilakukan oleh admin.

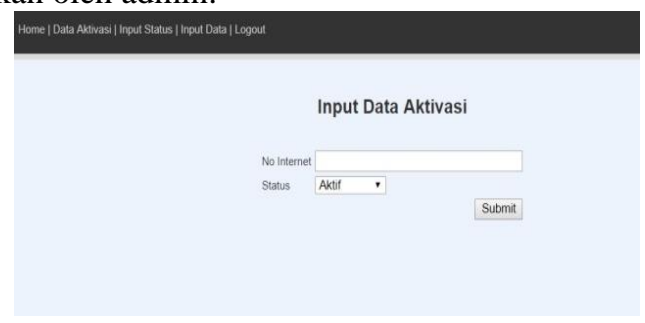

Gambar Form Data Aktivasi

\section{Form Data Aktivasi}

Form data aktivasi ini yaitu proses dimana admin akan mengecek keaktivan barang material yang di pasang teknisi memalui data aktivasi, karena ketika barang belum terpasang no internet di barang material akan menunjukan status tidak aktif.

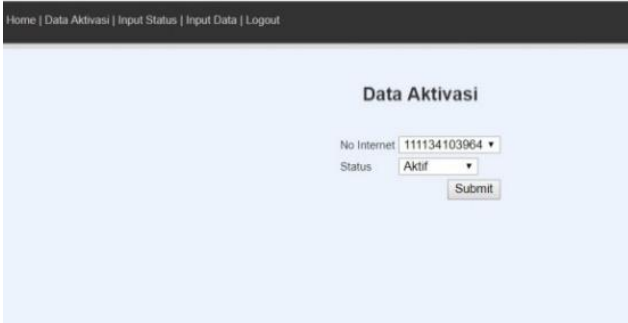

Gambar Form Data Aktvasi

\section{Form Status Aktivasi}

Form Status aktivasi akan menampilkan no internet yang sudah di input admin dan status aktiv atau tidak aktiv barang material yang sudah terpasang oleh teknisi, jika status tidak menunjukan keaktivan no internet maka Admin harus menginput data kembali.

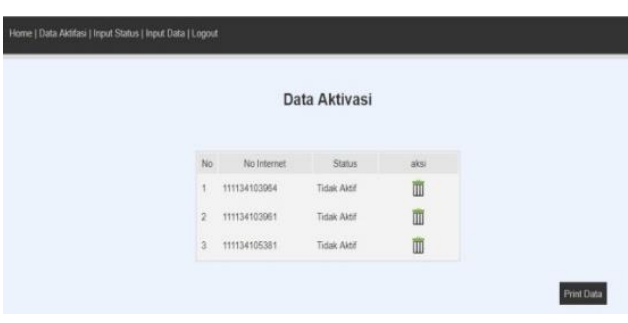

Gambar Form Status Aktivasi

\section{KESIMPULAN}

1. Pengembangan aplikasi SCMT ini telah berhasil melakukan pengecekan aktivasi pemasangan barang material ke pelanggan. Dengan begitu admin dapat melihat aktivasi pemasangan barang material ke pelanggan.

2. Pengembangan aplikasai SCMT ini di buat menggunakan DFD untuk membantu memahami sistem aplikasi, serta pengembangan aplikasi ini menggunakan ERD untuk menentukan relasi antar tabel.

\section{DAFTAR PUSTAKA}

Ariyanti, Nita. 2010. 'Sistem Informasi Pelayanan Instalasi Listrik PLN Kartasura. Surakarta: Universitas Sebelas Maret.'

Dannis Tanaka dan Nyoman Nurcaya. 2018.'ANALISIS KINERJA SUPPLY CHAIN MANAGEMENT BERBASIS BALANCED SCORECARD PADA PT. ALOVE BALI IND.'

Herman Kurniawan, dkk. 2018. 'PENGARUH BIAYA PRODUKSI, HUTANG JANGKA PANJANG DAN PENDAPATAN TERHADAP LABA BERSIH PERUSAHAAN DENGAN HARGA JUAL SEBAGAI VARIABEL INTERVENING PADA PERUSAHAAN MANUFAKTUR SEKTOR INDUSTRI BARANG KONSUMSI 
YANG TERDAFTAR PADA BEI TAHUN 2012-2016'

Joko Christian. 2010. 'MODEL DATA WAREHOUSE DENGAN SERVICE ORIENTED ARCHITECTURE UNTUK MENUNJANG SISTEM INFORMASI EKSEKUTIF'

Ludi Sheab Hamim, dkk. 2018. 'SISTEM INFORMASI EKSEKUTIF UNIT SECURITY AND SAFETY PADA PT. TELKOM KOTA BANDUNG'

M.Ardiansyah Sembiring, Zulfi Azhar. 2015. 'IMPLEMENTASI METODE ROUGH SET UNTUK MENGANALISA LABA/RUGI PADA SUATU PERUSAHAAN DISTRIBUTOR (studi kasus: usaha kita ps payakumbuh)'

Ninik Wulandari. 2014. 'Perancangan Sistem Pendukung Keputusan Pemilihan Supplier di PT. Alfindo Dengan Metode Analytical Hierarchy Process (AHP).' 